\title{
Cohabitation between Cartagena and Cartago Nova (Spain)
}

\author{
F. Segado Vázquez ${ }^{1} \&$ J. M. Maciá Albendín ${ }^{2}$ \\ ${ }^{I}$ Department of Architectural Constructions, \\ Polytechnic University of Cartagena, Spain \\ ${ }^{2}$ Polytechnic University of Cartagena, Spain
}

\begin{abstract}
When cities with great archaeological remains in their subsoil tend to grow and spread, there are a lot of factors which are forgotten to the detriment of the society. The way to deal with overlapped cities is not one of the abilities of archaeologists, who try to discover our origins but are not concerned about how these remains can be linked to the rest of city. Understanding how to combine old and new cities is a new growing problem that prevents the adequate development of cities. Urban developers work as hard as possible to find new solutions to combine history and modernity.

One of the most important figures is Pedro A. San Martín (1921-2013, Cartagena, Spain), who tried to develop new concepts and ideas about the valorization of the heritage. As an architect (a member of the Department of Fine Arts of the Ministry of Culture, Local Commissioner of Archaeological Excavations and Director of the Municipal Archaeological Museum of Cartagena), he promoted a multi-layered approach (technical and urban) in the pursuit of one central objective: the revaluation of the city in its entirety. San Martín tried to be an archaeologist among architects, explaining to them how they could coordinate their discoveries in order to achieve a viable relationship between the old and the new city in Cartagena. His subterranean works about the cohabitation of remains and new buildings are a great example of how both disciplines should be combined.

Keywords: archaeology, urbanism, Tarragona, Tarraco, Mérida, Émerita Augusta, Cartagena, Cartago Nova, Pedro A. San Martín.
\end{abstract}




\section{Introduction}

Much has been written over the last decades about the coexistence of overlapped historical cities in the same urban fabric. Most of it seems to have focused on the different social, economic and archaeological points of view, and tends to omit the most important discipline which must link all of them, i.e. urban development, that entails recovering the true essence of the composition and origin of the cities.

Archaeologists agree with architects about how this process must be planned but Local Administrations have a different point of view. Current laws and procedures tend to give importance to the evaluations, considerations and assessments.

The way in which archaeology deals with the findings and the conditions to which the findings are subjected make prediction and planning difficult in this discipline, since the professionals in this field cannot always address the most important tasks in the areas they would like, and do not even have the necessary funding to carry them out with a comprehensive programming where different potential socio-economic scenarios would not hinder their work.

In 1985, the Law 16/1985, of June 25, on the Historical Spanish Heritage [1] was enacted in Spain in order to give answers to the new situation regarding the procedures to preserve the archaeological remains. At the same time, "Archaeology of modern cities superimposed on old ones; Zaragoza 1983" was published; it is one of the first official studies about the conflicts that were starting to take form regarding the way of recovering the origins. The fact that both of them were published around the same time is not a mere coincidence and reveals a shift in the way of addressing and highlighting recovery projects. The aforementioned publication includes one of the first approaches of P. San Martín to the new urban conflict.

Later, in 2000, in the city of Granada (Spain), the sensitivity of this question was revealed in the course of the European Seminar on the Management of Historical City Centers [2], through different presentations. The most important of them develops the integration of heritage management in urban development [3], focusing on the issues of the city of Bergen (Norway). It is also an important focus how, in this conference, management in overlapped cities is shown taking the city of Mérida (Spain) [4] as the main reference.

All the works in this field started to take relevance and, as a result of it, in 2004, in the III International Congress about Exhibition of Archaeological Sites, a presentation was published on the project APPEAR (Accessibility Projects Sustainable Preservation and Enhancement of urban sub-soil Archaeological Remains) [5], developed in the period 2003-2005.

The project "APPEAR" presented new proposals of standardization in urban development action in order to highlight the heritage protected under different coordinated and related disciplines. It was funded by the European Commission (Contract EVK4-2002-00091) and included in the programme "The city of tomorrow and the Cultural Heritage". It was an innovative proposal aimed at a specific goal, a global action, although it could be considered insufficient. 
This project offered a guide on how to develop good urban practices regarding the action on archaeological sites or heritage assets, but it is probably based on a different point of view. Showing a catalogue of different sites or buildings of historical interest in different cities, it proposed the steps to follow in the process while forgetting the special characteristics of each city. A proposal aimed at highlighting only specific elements instead of interlinking the overlapped cities. All efforts have to be directed to generate a new model of city in which all the elements of the heritage are interrelated and interlinked.

We need to understand what is failing in order to know how to correct it. The present paper tries to analyze old methods and its consequences, in order to define a modus operandi in dealing with archaeological remains.

Therefore, the key findings of this research must be:

- Define cities whose characteristics are similar to those of the Roman Age.

- Define patterns of urban projects and plans in cities of similar characteristics.

- Set out the legal and urban plans of action.

- Research the involvement of architects in archaeological excavations in the studied cities.

- Draw conclusions regarding the results and consequences of the involvement of architects in the archaeological works in the studied cities, especially in Cartagena (Spain).

\section{Analysis by comparison}

To understand the layout of a Roman city by taking into account only the different buildings seems to be impossible. All of them have to be considered from the outset as an inseparable part of the whole to which it gives sense.

We have many significant examples of action aimed at highlighting the archaeological heritage in Spain, although its final purpose moves away from the objective of linking and integrating two cities into one.

Some examples of these proposals are Zaragoza (the Forum and the Theatre Museums, the Museums of the Thermal Baths and the Fluvial Port) [6], Seville (the Castle of San Jorge and the Incarnation) [7], Cadiz (the surroundings of the Roman Theatre) [8] and Jaen (the Square of the Orphans and the Square of Martos Door) [9].

All of them are examples of partial, and probably timid, action, where we can detect a lack of urban development plans. Probably, the development of ideas in Zaragoza and Seville has been more important, but this possibility justifies a lack of global laws because it is easy to think that only bigger efforts are carried out in bigger cities. Governments are giving importance depending on the size of new cities instead of the importance of the heritage under the city.

If we make a comparative analysis of different Spanish cities we will be able to understand the current situation that has led to such disparate actions under the same regulatory framework. This fact reveals the lack of a standardized procedure to highlight the historical heritage by linking it to the city development.

Let us take Tarragona and Mérida as elements of reflection and comparative analysis, contemporary, distant and with different configurations at present, but 
with meticulous museum work. The relationship between both cities is also understood in military terms. While both were military cities in Roman times, the colony of Tarraco was considered to be a billeting city and Emeritus Augustus became a destination for retired soldiers. Similar history and characteristics are the main factors to select them as comparative elements with the studied city, Cartagena.

Understanding the valorization of the heritage of these three cities and the relationship with urban plans, we will be able to conclude how new methods can help our society to recover its origin.

\subsection{Coexistence in Tarragona}

Being one of the Spanish cities with the greatest legacy of the Roman times given its importance as a colony in the imperial epoch - we can use the archaeological and urban development works carried out in this city to understand the coexistence of both disciplines. Making a short historical introduction, we should bear in mind a quote of J. Ruiz de Arbulo about this city: "Tarragona, in Latin Tarraco, provides us with a memorable example of those cities that after having astonished the universe with their brilliance, their expansion and their power disappear in an instant and only preserve a famous name and a sterile recollection of their past glory. This city, one of the most notable of the Roman Empire, the first one of the Hispanic provinces, headquarters of the praetors, center of power of the republic of Rome, is reduced today to an enclosure of three scanty quarters of league of circumference and to a population from 9 to 10.000 souls, very simple buildings and a condition not far from poverty" [10].

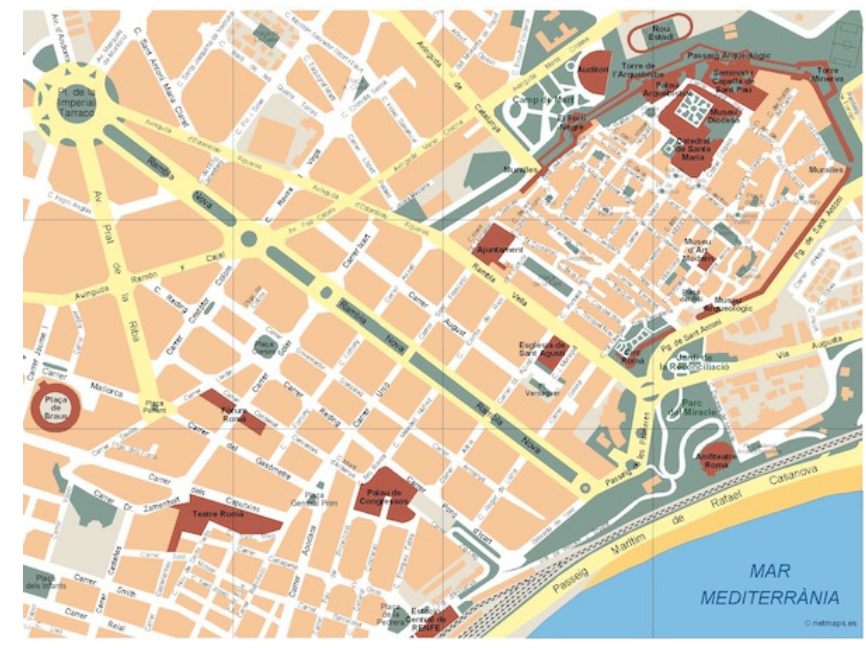

Figure 1: Map of the city of Tarragona.

Making a simple analysis on a current map of this city, we can describe a welldefined historical center surrounded by a clear enlargement structure, approved in 
1857 under the project of the Engineer Commander Ángel del Romero [11]. It consists of two plots, well defined from a town planning perspective, with a clear pattern where the defining axes of the Roman can be gently distinguished, beyond the delimiting of the walls.

Historically, the declaration of the whole city as Historical Artistic Set (D 652/1966, BOE 22/III/1966) takes place in 1966, defining three areas: the historical center, entirely protected; a respected area, with archaeological plans and control of heights and volumes of the buildings to preserve the urban silhouette; and a few zones of enlargement just submitted to archaeological control. The above mentioned gradation emphasizes the differentiation of zones instead of pursuing global and joint action inside the whole city.

The declaration of 1966 was left in the hands of the Archaeological Provincial Museum, the accomplishment of the excavations in those cases foreseen by the Law. In 1967, P. M. Berges, took charge of the direction of the MAP until 1978. Under Berges' direction different reforms in the museum and important excavations were carried out in the Villa dels Munts, the square of the Foro, the Antiga Audiencia and the Roman Theatre. In these years, the MAP had limited economic and human resources to carry out the archaeological interventions imposed by the law. Furthermore, apart from a few exceptional findings, the Museum lacked effective legal instruments of pressure against the private builders or the different administrations. In spite of it, they managed to achieve diverse and very meritorious interventions, but certainly there did not exist any foreseen relationship between the urban development studies of the archaeological heritage and the planning and development of the city and of its environment.

Although the aforementioned declaration allowed the city to start new works in these disciplines, the real recognition was made in 2000, when the Roman ruins of Tarraco was designated a World Heritage Site by UNESCO.

Some of the most important Roman buildings included in the declaration of the city by UNESCO are the Roman walls, the capitol, or citadel, the Amphitheatre, the Roman Circus, the Pretorium - Tower, the Forum, the Necropolis, the Palace of Augustus, the Arch of Sura, and the Aurelian Way.

In a deep analysis, we can appreciate in detail how an effort was made to reveal the old city, though a cautious one in some areas.

From this perspective, old remains seem to make no sense and the valorization disappears as a real option.

The old urban plan can be distinguished near the walls, in the old city where the new and orthogonal urban plans tend to copy or assimilate old remains. Due to this, the remains appear in different places without an apparent and logical connection and have to be interpreted by an archaeologist who cannot do anything to integrate them in a whole.

Clearly, the urban development approaches of the city are older than the archaeological ones, which date back to only a few decades ago. However it is strange to see how archaeology has removed the concept of urban development instead of trying to integrate it. Attention is paid to small spots in the city rather than to the whole city; some parts of it acquire more importance than the whole. 


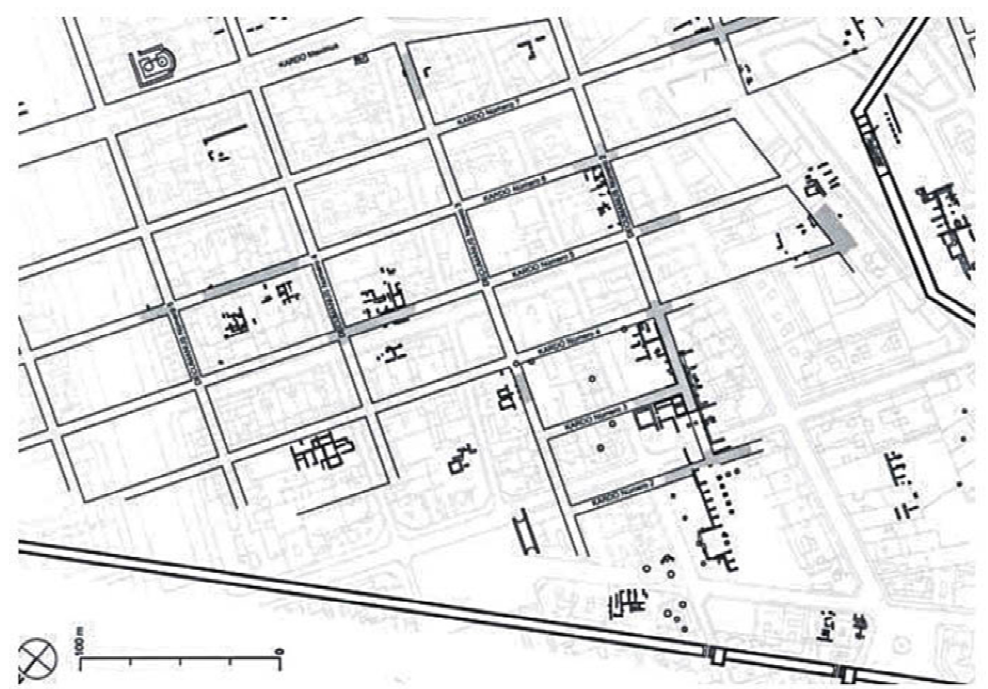

Figure 2: Overlapped cities.

Many studies and works have to be done by the Local Administration if they really want to recover and interrelate the old city. Making itineraries in which the visitors can be involved in a different age is not enough to give the city the entire heritage that its subsoil has.

\subsection{Coexistence in Mérida}

Once we have analyzed the most similar city in Spain during the Roman Empire, it could be accurate making a study about how another city, even more important than Cartago Nova, has carried out the valorization of its heritage and has interlinked - if it has done - the old and new cities through urban plans or urban development.

As an introduction, the importance of the city can be shown by a quote of archaeologist, J. M. Blázquez Martínez: "The Lusitania's capital, Emeritus Augusta, founded by emperor Augustus in 25 BC, a few years after the beginning of the Cantabrian Wars as part of his legacy to settle the war veterans, is one of the Hispanic cities that offers most information to study a topic that has become fashionable in the research of the Ancient World today: that of the relationship between town development and religion" [11]. In his "Studies on the archaeological set of Emeritus Augusta" on the city of Mérida, he emphasizes the importance he attaches to town development as a shaping element of the city.

UNESCO appoints that, "Mérida is symbolic of the process of Romanization in a land that had hitherto not been influenced by the urban phenomenon. It contains the substantial remains of a number of important elements of Roman town design, considered to be one of the finest surviving examples of its type; the aqueducts and other elements of Roman water management are also especially well preserved and complete". 
The first works of archaeology and town development were carried out in Mérida in the mid-seventies, last century. They set the foundations of what must be the interaction between both disciplines to obtain, as result of the works, a whole which interlinks the Roman city with the current one. It was a declaration of intentions that acquired more relevance from 1984 with the transfer of competences in this area from the Central Government to the Local Administrations and the creation at the time of the City's Historical-Artistic and Archaeological Trust, supported by the Law 16/1985, of June 25, on the Historical Spanish Heritage [1]. On the other hand, when this trust was created, there was talk about the problem entailed by the fact that there were not enough archaeologists. However, having more town planning architects, experts in archaeology, that could add more accuracy to the project as a whole, did not seem a problem.

In 1996, the Consortium of the Monumental Historical-Artistic and Archaeological City of Mérida was born, with mainly an archaeological nature. The Department of Culture, the Council of Culture of the Autonomous Region of Extremadura, the County Council of Badajoz and the Town Hall of Mérida were part of it. The Consortium set out the goals of preserving, supporting and revaluing the monumental city as well as the study and assessment of its remains to integrate them in the city, but did not address the external collaboration of any architects, either through an architect's association, an independent firm or even university departments involved in the planned tasks.

In fact, there were many studies carried out on the original configuration of the urban development but it was historian Álvaro Corrales Álvarez who indicated that "In spite of abundant archaeological literature on some aspects relative to decoration or morphology, to date, there is no global vision that integrates the study of its architecture, its ornamental programme, its material culture and their insertion in the urban plot, all of them explanatory factors of great interest at present, due to the development that domestic architecture in Hispania has experienced in the last decades" [12].

The Local Administration offers technical personnel to carry out these works, which are mainly orientated to the review and control of the fulfilment of the initial aims, eliminating the possibility of a continuous follow-up by a committee of experts. In this way we can see how the aims set for the city are fading away due to the absence of interdisciplinary workgroups in which expert town planners support and guarantee the success of the initial approaches.

Among the most important remaining Roman monuments are Puente Romano; remains of the Forum, including the Temple of Diana, and of the Roman Provincial Forum, including the Arch of Trajan; the Circus Maximus (1st century BC), one of the best preserved Roman circus buildings; Aqueduct of the Milagros, the Amphitheatre, the Roman theatre, Morerías archaeological site.

The Roman remains of Mérida was designated a World Heritage Site by UNESCO in 1993 under a natural and cultural vision.

A plan of Mérida where we could locate the different sites under study or highlighted gives us a vision of seemingly unconnected elements spread around 
this urban network, as if somebody had made a hole in order to avoid the image of a degraded city instead of showing the relationship between each element found.

A large historical center can be seen, delimited by the walls of the city and crossed by the river Guadiana. In the same way, a concentric growth of the city around the historical center can be identified but we cannot recognize the orthogonal pattern, mentioned in some studies on town planning of the Roman times.

As we see in Tarragona, the old urban plan cannot be distinguished and welldefined near the walls, in the old city where the new and orthogonal urban plans tend to copy or assimilate old remains. Due to this, the remains appear in different places without an apparent and logical connection and have to be interpreted by archaeologist who cannot do anything to integrate them in a whole.

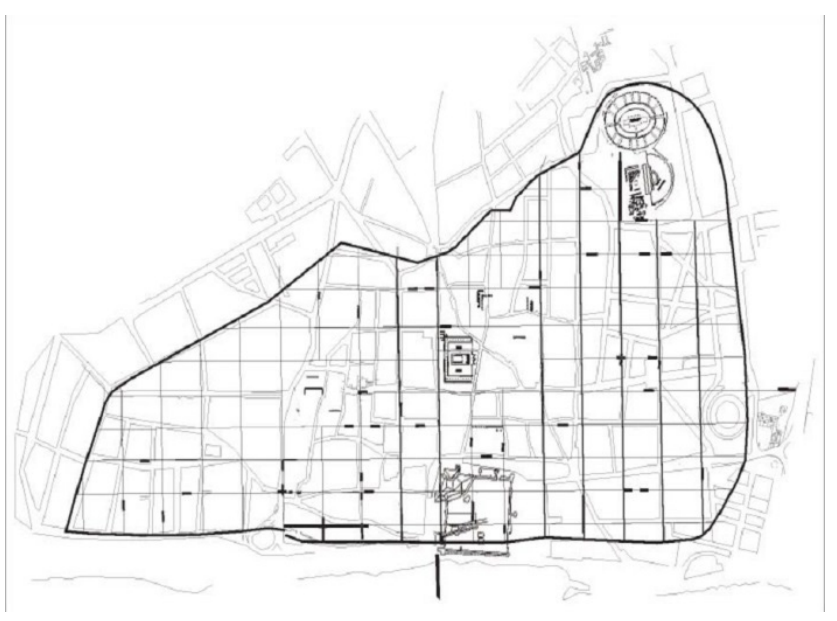

Figure 3: Overlapped urban plans in Mérida.

Without the particular knowledge of every discipline, it turns out impossible to determine why each city is in the site in which it is located and which is the relationship and proportion between them; in the same way, it is impossible to identify the road network of the Roman city. There are no links between both cities nor any connecting element. Simply one city dwells over the other, so that the plots opened in the current mapping seem to be windows on the past. Big windows, that is, but windows that nonetheless give us the feeling of reading history in long sentences that prevent us from contemplating the details that would have allowed a better recreation of those times. Archaeology begins to lose the social nature that it should have as a means of educating the city's inhabitants on their history to become a catalogue of real estate (at best) or mere remains of them.

Thus, we can see that archaeology does not consider town development as the necessary companion for highlighting the archaeological heritage. Instead it considers urban planning as the discipline that should link the punctual findings omitting, from the start, a global vision that might simplify the study and give an extra value to the different local systems of planning. 


\section{Cartagena over the foundations of Cartago Nova}

In the southeast end of the Iberian Peninsula, in an intermediate section of the Vía Augusta, delimited by five hills/Arx Asdrubalis, current Hill of Molinete, and the Mons Saturnii, Aletis, Vulcanii and Esculapii (the latter identified as the Mount of the Concepcion), one finds the colony of Cartago Nova. Founded on the remains of previous civilizations, its original morphology is the consequence of the complex orography that prevents its access and expansion, facilitating its defense and relevance in the epoch, a product of the mining wealth of the region.

Although other works about the valorization of the heritage were started in previous centuries, the most important works are led during the middle of the 20th century, in 1943, by Antonio Beltrán Martínez, assistant of the University of Murcia (1945-1949). He started highlighting Cartagena's local heritage by formally proposing its Town Hall for the establishing of an Archaeological Museum that would exhibit the numerous remains recovered in different archaeological excavations in the city. Shortly afterwards, Antonio Beltrán, Emeterio Cuadrado - Assistant Mayor and Town Councillor of Culture in the Town Hall of Cartagena - and Mariano Pascual de Riquelme created a municipal committee with the aim of creating the Museum of Municipal Archaeology.

The Urban Development Department of the city recognized the following: "The urban development situation in Cartagena was really chaotic. Although the first General Plan of Cartagena, drafted by the Ministry of Housing, had been approved in 1961, the development of city paid no attention whatsoever to the Plan, both in this decade and in the following one. In 1976, the Ministry of Housing approved a modification of the General Plan, which regulates the heights and the uses of buildings in the old part of town and in the area of the enlargement, and classified as urban soil the settlements of the interior and the beaches, for their development by means of PERI. Furthermore, in 1977, the "General Plan of Beaches", which regulates the coastal soil, is approved by means of positive silence. Thus, Cartagena becomes a town regulated by two general, contradictory Plans".

The Law 16/1985, of June 25, on the Historical Spanish Heritage [1], can be considered as a milestone in local town planning. However, in the case of Cartagena is particularly relevant, since the approval of this Law coincides with the drafting of the General Plan of Urban Regulation of Cartagena (1987).

The solution raised for the previous problem established the following: "In the area of the Historical Set of Cartagena, the General Plan has the consideration of a Special Plan of Arrangement and Protection (PEOP), since it contains the rules for the protection of the Archaeological Heritage, as well as the historical-artistic heritage, by means of the inclusion of aesthetic rules and the Catalogue of protected buildings. These dispositions are replaced by the Special Plan of Arrangement and Protection of the Historical Set, PEOP CH, partially approved by Plenary Agreement of March 3, 2005, and in its entirety by the Agreement of November 7, 2005, having taking notice of the Merged Text by means of the Decree of the Vice-president of the Management Department of May 8, 2006". 
Among its most important remains, we can find its Forum, located in the crossing between the Cardo and the Decumanus, which is established in the central part of a city and presents a great variety of public and monumental buildings of the epoch, as the Theatre, the Amphitheatre, and the Thermal Baths.

The old urban plan can be distinguished and well defined in the most important axis of the city where the new and the orthogonal plan fight to be identified. Due to this, the remains appear in different places without an apparent and logical connection and have to be interpreted by archaeologist who cannot do anything to integrate them in a whole.

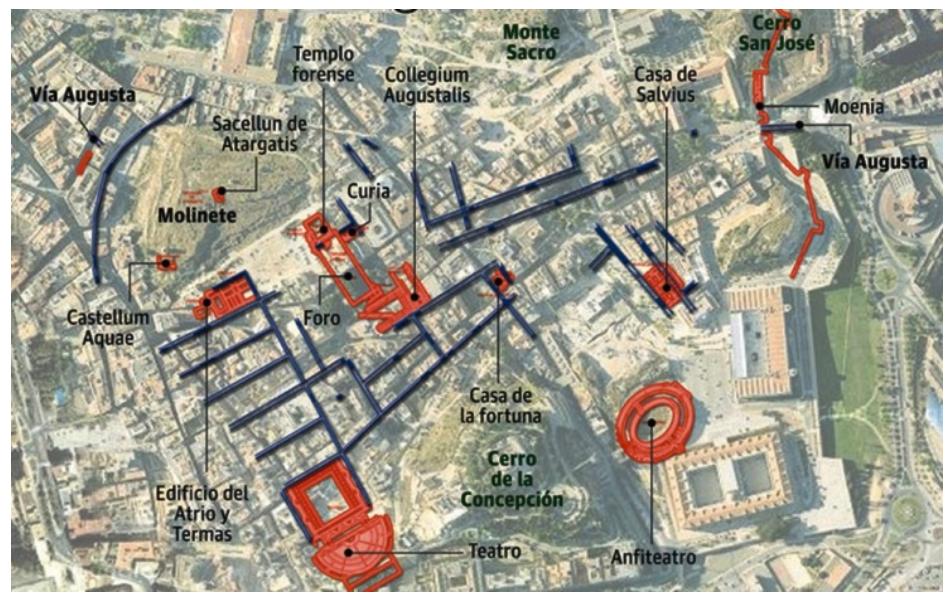

Figure 4: Overlapping of urban plots in the city of Cartagena.

Solutions to isolated problems and solutions to global problems are perceived, so that the proposed legislation tries to solve the issues previously raised but does not define with clarity the future scenarios of coexistence between archaeology and town development.

Understanding that it was impossible to destroy the new city, P. San Martín set out how to create a new city next to the foundations of the old one, making new itineraries and new ways to walk and know the city.

\subsection{The role of Pedro A. San Martín}

In 1954, Pedro A. San Martín, an architect, was transferred to the State Finance Delegation in Cartagena. In the same year of his arrival in the city he was designated local commissioner of Archaeological Excavations. In this capacity, he started numerous projects, interventions and explorations, and continued Antonio Beltrán's works in the defense of the study and conservation of the archaeological remains that had appeared across the numerous excavations carried out in the historical centre.

In 1975, San Martín was considered one of the most important experts in the archaeological possibilities of Cartagena and being aware of the issues regarding 
the coexistence of superimposed cities and knowing the economic implications for the real-estate sector, he considered that making large expropriations could lead to the deterioration of the city and deter potential investors due to the difficulties of initiating real-estate development projects.

Being a true expert of the findings in the city and convinced of the potential that this particular one could have, he decided to apply new building techniques to his projects that would allow preserving all the archaeological findings while reducing the economic impact on building companies.

He then considered preserving the findings in the basements and ground floors of the buildings, so that in a continuous way, it is possible to visit the remains of the Roman city under the current urban development. Two articulated, readable cities arranged in different strata. A new way of understanding and crossing a city where its inhabitants or visitors can plunge into the ways of living experienced 2000 years ago.

In the General Plan of Urban Regulation of Cartagena (1987), Pedro San Martín, as an architect and in a personal capacity, aimed at preserving the historical heritage by means of proposing a more exhaustive catalogue than the one included in the new Law for the new General Plan that, in his opinion, was contrary to the environmental interest. He requested the inclusion of up to four protection degrees in the General Plan Protection Catalogue, out of which three were finally approved. The consequence of this delay resulted in the impossibility of incorporating the PERI (Special Plans of Interior Reform) into the structure of the finally approved document.

\section{Conclusion}

In spite of the fact that the Law 16/1985, of June 25, on the Historical Spanish Heritage [1] constitutes the cornerstone in local town development, allowing deeper awareness regarding exhibition and highlighting works, urban plans have started to interlink old and new cities and only try to preserve the remains.

In the cities studied by comparison we cannot establish an original pattern from Roman cities and only through recent works an old pattern can be established in old cities.

By means of the proposed system of exhibition of the Heritage - which delimits clearly the surface of the different archaeological sites - physical barriers are created that only allow to cross and understand parts of the Roman city and not its unitary structure.

In Cartagena, the above mentioned actions were carried out during the first years under the direction of architect Pedro A. San Martin, in order to bring together urban development, and archaeological and business projects.

When he had stopped his professional activity due to his age, his work was continued by archaeologists whose aim was the preservation of the historical wealth of the city but who forgot the need to interlink the archaeological findings with the structure of the city.

In consequence, all the efforts made by Pedro San Martín during the second half of the 20th century have not had continuity in the context of urban 
development. This, in turn, has triggered a series of actions aimed at enriching the historical-artistic heritage of the city while avoiding references to the original fabric and losing a unique pioneering opportunity in the works for the recovery of historical plots.

\section{References}

[1] Law 16/1985, of June 25 of the Historical Spanish Heritage. Published in BOE of June 29, 1985.

[2] European Seminar of Management of Historical City Centres. Granada, 2000.

[3] Myrvoll, S. The city inside the city: the integration of the patrimonial management in the modern urban development. European seminar of Management of Historical City Centres. Granada, (2000).

[4] Mateos Cruz, P.: The patrimonial management in a city superposed to an archaeological deposit: the model of Mérida. European Seminar of Management of Historical City Centres. Granada, (2000).

[5] Asensio. M., Colomer. L., Ruiz J., \& Sanz N. APPEAR Project: The city and the valoritzacion of the European archaeological heritage. III International Congress about Exhibition of Archaeological Sites, pp. 225228. Zaragoza, (2004).

[6] Aguarod. C., Erice. R. \& Mostalac A., Caesaraugusta, four themes for a single urban context. III International Congress about Exhibition of Archaeological Sites, pp. 137-143. Zaragoza, (2004).

[7] Amores F., González D. \& Jiménez A. The valoritzacion of the archaeological remains of the incarnation and the emergence of a new heritage stage in the city of Seville. III International Congress about Exhibition of Archaeological Sites, pp. 235-238. Zaragoza, (2004).

[8] Esteban J.M., Muñoz A. \& Blanco F.J. Brief history and criteria of intervention in the urban area of the Roman theatre of Cadiz. Roman theatres of Roman Spain, pp. 141-156. Notebooks of Roman Architecture, Vol 2. (1993).

[9] Barba V., Alcalá F., Navarro M. \& Arias F. Prospects for the creation of new spaces Museum in the historic public places. III International Congress about Exhibition of Archaeological Sites, pp. 25-29. Zaragoza, (2004).

[10] Ruiz J., Mar R. 1999: Archaeology and town planning in Tarragona. Tradition historiográfica and current reality, to recover the urban memory. The Archaeology in the rehabilitation of the historical cities (Tarragona 1997), URV/Fund. La Caixa, Tarragona.

[11] Blázquez J.M. Religion and Urbanism in Emeritus August. Antigua. History and Archaeology of the civilizations. Spanish file of Archaeology, núm. 55, pp. 89-106. Virtual library Miguel de Cervantes. (1982).

[12] Corrales, A. Religion and Urbanism in Emeritus August. Antigua. History and Archaeology of the civilizations. Spanish file of Archaeology, núm. 55, pp. 89-106. Virtual library Miguel de Cervantes. (1982). 